\title{
Qualitative Variable
}

National Cancer Institute

\section{Source}

National Cancer Institute. Qualitative Variable. NCI Thesaurus. Code C142657.

Variables that cannot be represent by a number, used to describe data that fits into categories. 